\title{
Behaviors Related to Mosquito-Borne Diseases among Different Ethnic Minority Groups along the China-Laos Border Areas
}

\author{
Chao Wu ${ }^{1,2,+}$, Xiaofang Guo ${ }^{1,+}$, Jun Zhao ${ }^{2,3}$, Quan Lv ${ }^{1}$, Hongbin $\mathrm{Li}^{4}{ }^{\text {, Edward B. McNeil }}{ }^{2}$, \\ Virasakdi Chongsuvivatwong ${ }^{2, *}$ and Hongning Zhou ${ }^{1, *}$ \\ 1 Yunnan Institute of Parasitic Diseases, Puer 665000, China; wuchao_simao@163.com (C.W); \\ yipdgxf@163.com (X.G.); lvquan2001@163.com (Q.L.) \\ 2 Epidemiology Unit, Faculty of Medicine, Prince of Songkla University, Hat Yai, Songkhla 90110, Thailand; \\ stzhao@163.com (J.Z); edward.m@psu.ac.th (E.B.M.) \\ 3 Hubei University of Medicine, Shiyan 442000, China \\ 4 Xishuangbanna Prefecture Center of Disease prevention and Control, Jinghong 666100, China; \\ bannacdcjfk@163.com \\ * Correspondence: cvirasak@gmail.com (V.C); zhouhn66@163.com (H.Z.); \\ Tel.: +66-74-451165-6 (V.C.); +86-0879-2122152 (H.Z.); Fax: +66-74-455150 (V.C.); +86-0879-2122153 (H.Z.) \\ + These authors contribute equally to the work.
}

Received: 15 September 2017; Accepted: 12 October 2017; Published: 15 October 2017

\begin{abstract}
Background: In China, mosquito-borne diseases are most common in the sub-tropical area of Yunnan province. The objective of this study was to examine behaviors related to mosquito-borne diseases in different ethnic minority groups and different socioeconomic groups of people living in this region. Methods: A stratified two-stage cluster sampling technique with probability proportional to size was used in Mengla County, Xishuangbanna Prefecture, Yunnan. Twelve villages were used to recruit adults ( $\geq 18$ years old) and eight schools were used for children ( $<18$ years old). A questionnaire on behaviors and environment variables related to mosquito-borne diseases was devised. Results: Multiple correspondence analysis (MCA) grouped 20 behaviors into three domains, namely, environmental condition, bed net use behaviors, and repellent use behaviors, respectively. The Han ethnicity had the lowest odds of rearing pigs, their odds being significantly lower than those of Yi and Yao. For bed net use, Dai and other ethnic minority groups were less likely to use bed nets compared to Yi and Yao. The odds of repellent use in the Han ethnicity was lower than in Yi, but higher than in Dai. The Dai group was the most likely ethnicity to use repellents. Farmers were at a higher risk for pig rearing and not using repellents. Education of less than primary school held the lowest odds of pig rearing. Those with low income were at a higher risk for not using bed nets and repellent except in pig rearing. Those with a small family size were at a lower risk for pig rearing. Conclusion: Different ethnic and socioeconomic groups in the study areas require different specific emphases for the prevention of mosquito-borne diseases.
\end{abstract}

Keywords: behaviors; mosquito-borne diseases; bed nets; repellent; environment; multiple correspondence analysis; ethnic group

\section{Introduction}

Yunnan Province, China, located at the southwest border of mainland China with an area of $394,000 \mathrm{~km}^{2}$, shares international borders with Myanmar, Vietnam, and Laos. More than 10 types of arboviruses have been isolated in the area and its neighboring Southeast Asia countries. These include Japanese encephalitis virus (JEV), dengue virus (DENV), chikungunya virus (CHIKV), and Zika virus (ZIKV). From 2008 to 2016, DENV outbreaks were reported in Yunnan Province and Laos. 
Two serotypes (DENV-2 and DENV-3) and CHIKV as well as their co-infections were observed [1]. DENV, causing the 2013 autochthonous outbreak, was shown to be genetically linked to DENV circulating in the north of Laos [2].

Among mosquito-borne diseases (MBD), prevention and control behaviors such as repellent use and bed net use are key actions that individuals can take. The Chinese government has various programs to improve behaviors to reduce the prevalence of mosquito-borne disease in the population. There are 26 ethnic groups settled in China-Laos border areas. In Mengla County (study site), the population of ethnic groups represents $70 \%$ of the total. Among them, Dai, Aini, Yao, and Yi are the primary groups. The Fifth Round China of Global Fund Malaria Project in 2007 showed that in Yunnan MBD endemic areas, $65.8 \%(25,797 / 39,234)$ of households owned at least one net and $8.7 \%$ $(3404 / 39,234)$ owned at least one impregnated treated net (ITN) [3]. In 2010, the coverage and use of impregnated treated nets and long-lasting impregnated nets (LLINs) increased to $89.7 \%$, and $30.6 \%$ (789/2582) slept under LLINs or ITNs at night [4]. However, the report focused on only three ethnic groups [5-7]. There has been no study on how the local residents of different ethnic groups and different socioeconomic groups vary their MBD prevention behaviors.

In 2016, a survey was conducted to estimate the sero-prevalence of various mosquito-borne diseases in this area. The results on serology are still not available as they need to be verified by highly accurate but time-consuming neutralization tests, in order to minimize the problem of cross-reaction and co-infection. In this communication, we report only the behaviors related to mosquito-borne diseases. As different ethnic groups have different lifestyles [5-7], we hypothesize that they will also have different behaviors related to mosquito-borne diseases. The objective of this study was to examine behaviors related to mosquito-borne diseases in different ethnic minority groups and different socioeconomic groups of people living in this region. The information from this study would be used for various mosquito-borne disease prevention and control efforts in this area.

\section{Materials and Methods}

\subsection{Ethical Consideration}

Ethical approval was obtained from the Institution Ethical Review Committee of Prince of Songkla University on 2 November 2016 (project code REC 59-244-18-5) and that of the Yunnan Institute of Parasitic Diseases. Informed consent was obtained from all subjects and related authorities including the guardians of subjects under 16 years of age.

\subsection{Study Site and Study Design}

The study was conducted in Mengla County of Xishuangbanna Prefecture, Yunnan Province, which has a $678 \mathrm{~km}$ border with Laos and a $25 \mathrm{~km}$ border with Myanmar as shown in Figure 1. The mean altitude is $1000 \mathrm{~m}$; the annual mean temperature is $21^{\circ} \mathrm{C}$, and the annual total precipitation is $1540 \mathrm{~mm}$. 


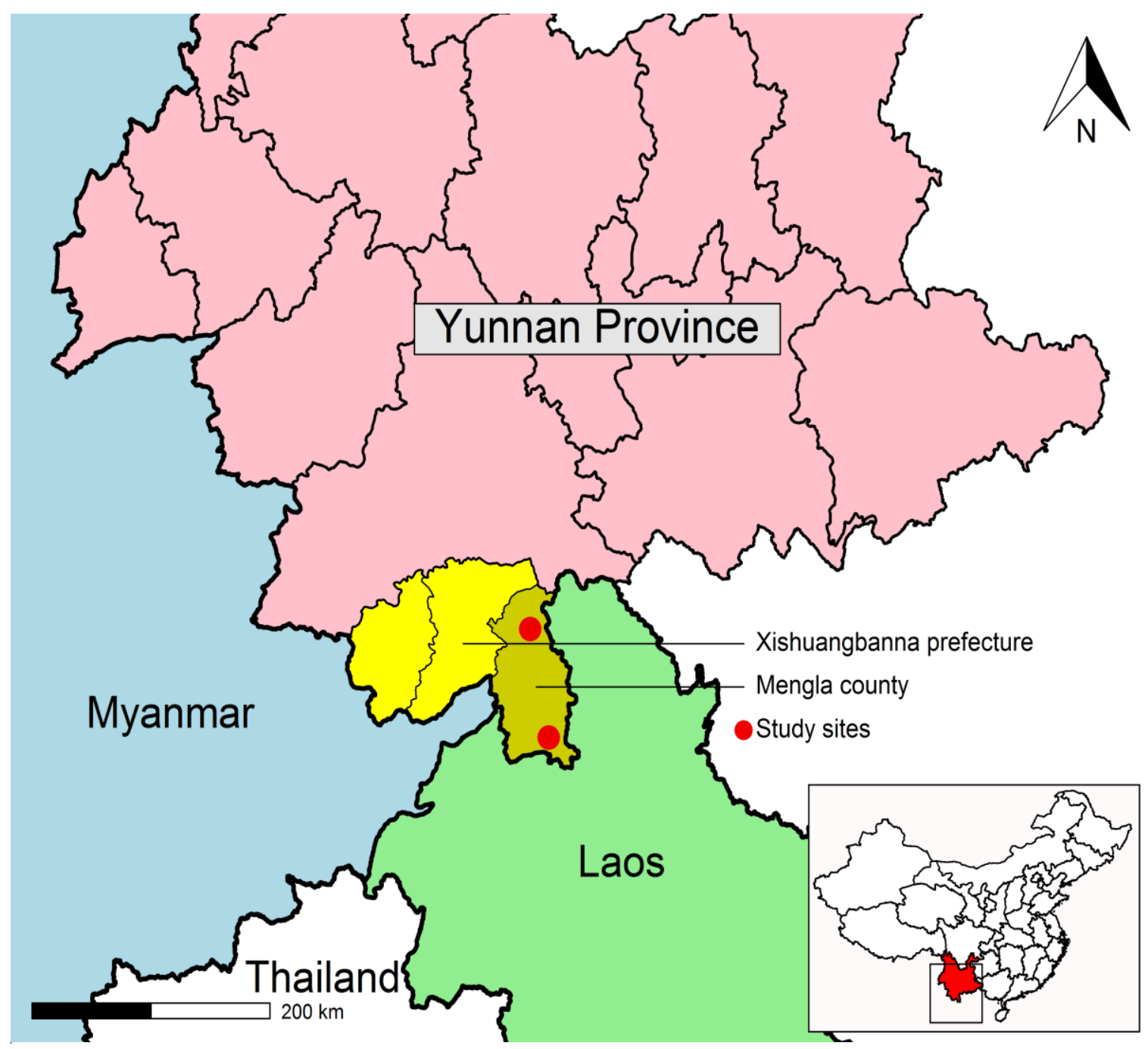

Figure 1. Map of study sites.

A cross-sectional survey was conducted from 12 to 30 September 2016. A structured questionnaire was devised and piloted before being used to collect information. It included the sociodemographic background of the individual behavioral and environmental factors related to mosquito-borne diseases.

\subsection{Sampling Technique}

A stratified two-stage cluster sampling technique with probability proportional to size was used. The first stratum was adults ( $\geq 18$ years old). The second was children ( $<18$ years old). In the first stage, five towns of Mengla County were selected randomly using computer software. In the second stage, in each selected town, villages and classes of primary and middle schools were chosen randomly. Finally, 20 clusters were used, which included 12 villages for the adult study and eight schools for the child study.

\subsection{Study Participants}

In each cluster, participants were randomly (using computer software) recruited from the list of adults in each village or a list of 6-18-year-old students in the selected schools. Inclusion criterion was being a resident of the study village for more than six months. Those who had serious hematologic system or immune diseases were excluded. 


\subsection{Questionnaire and Measures}

A structured questionnaire was developed to obtain the information from each participant, and was piloted in a village and a school not included in the main study before being used in the field. We developed the same questionnaire for adults and children for the reasons of comparability and possible data pooling in the analysis. The questionnaire contained four sections: (1) sociodemographic characteristics such as age, gender, ethnicity, education level, occupation, family size, and annual family income; (2) environmental variables such as pig rearing by family, distance from house to pig farm, with pig farm near the house, distance of the nearest pig farm, with paddy field, near to the forest, with rubber planting, with discarded tires, with aquatic plants, with pickle jars, with running water, and with tanks for water storage; (3) behavioral bed net use including possessing a bed net, frequency of bed net, and sleeping in a bed net in the daytime; (4) behavioral insect repellent use including using mosquito coil, floral water, and DEET (diethyltoluamide) when working or engaging in activities outside the house.

\subsection{Data Management and Analysis}

Data were recorded using EpiData (version 3.1, EpiData Association, Odense, Denmark, http://www.epidata.dk). All analysis was performed using R (version 3.4.0, R Foundation for Statistical Computing, Vienna, Austria. https:/ / www.R-project.org).

Twenty behavior variables in the current study were mostly categorical. Multiple correspondence analysis (MCA) was used to reduce the number of these variables into three dimensions using the "FactoMineR" package in R [8,9]. Details of the methods and results are described elsewhere (paper submitted to the Journal of Thai Interdisciplinary Research). The scores of each dimension were extracted and dichotomized as below the factor mean (low score for that dimension) and high score.

Univariate associations between sociodemographic variables and each dimension were explored using tabulation followed by chi-squared test. This was followed by multiple logistic regression analyses to adjust for confounders. The level of association was expressed as an odds ratio, and $p$ values below 0.05 were considered as reaching statistical significance.

\subsection{Sample Size Calculation}

To estimate the prevalence of a risk behavior, we assumed 50\% prevalence. With $95 \%$ confidence interval of the prevalence deviating $6 \%$ from the estimate and a design effect of 2 , the sample size required for each age group was 534 . We initially planned for 10 clusters for each age group, or around 54 participants per cluster.

\section{Results}

\subsection{Descriptive Statistics}

The actual sample size slightly deviated from what was planned. A total of 1295 participants were included the study, coming from five towns and 20 clusters (eight schools contributing 720 students and 12 villages contributing 545 adults). The personal backgrounds of these two groups are summarized in Table 1. Imbalances in the distribution of gender, ethnic group, family size, and family per capita income of the respondents were seen. We did not test their statistical significance, as these are all settings rather than only those that affect our hypothesis. However, we kept those independent variables for the adjustment of the final results on behavior and environment. 
Table 1. Sociodemographic characteristics.

\begin{tabular}{|c|c|c|c|c|}
\hline \multirow{2}{*}{ Characteristic } & \multicolumn{2}{|c|}{ Adult Group (>18 Years) } & \multicolumn{2}{|c|}{ Child Group ( $\leq 18$ Years) } \\
\hline & Frequency & Percent & Frequency & Percent \\
\hline Number of clusters & 12 & 60.0 & 8 & 40.0 \\
\hline Number of participants & 565 & 43.6 & 730 & 56.4 \\
\hline \multicolumn{5}{|l|}{ Gender } \\
\hline Male & 185 & 32.7 & 397 & 54.4 \\
\hline Female & 380 & 67.3 & 333 & 45.6 \\
\hline \multicolumn{5}{|l|}{ Education level } \\
\hline Less than primary school & 214 & 37.9 & 14 & 1.9 \\
\hline Primary school & 310 & 23.0 & 405 & 55.5 \\
\hline Secondary school or above & 221 & 39.1 & 311 & 42.6 \\
\hline \multicolumn{5}{|l|}{ Ethnicity } \\
\hline Han & 55 & 9.7 & 93 & 12.7 \\
\hline Dai & 105 & 18.6 & 82 & 11.2 \\
\hline Aini & 125 & 22.1 & 102 & 14.0 \\
\hline Yi & 157 & 27.8 & 144 & 19.7 \\
\hline Yao & 102 & 18.1 & 154 & 21.1 \\
\hline Other & 21 & 3.7 & 155 & 21.2 \\
\hline \multicolumn{5}{|l|}{ Occupation } \\
\hline Farmer & 453 & 80.2 & 8 & 1.1 \\
\hline Student or other & 112 & 19.8 & 722 & 98.9 \\
\hline \multicolumn{5}{|l|}{ Family size } \\
\hline$\leq 3$ & 127 & 22.5 & 70 & 9.6 \\
\hline $4-5$ & 258 & 45.7 & 441 & 60.4 \\
\hline$\geq 6$ & 180 & 31.9 & 219 & 30.0 \\
\hline \multicolumn{5}{|c|}{ Annually family income (CNY¥ per capita) } \\
\hline$\leq 8000$ & 193 & 34.2 & 123 & 16.8 \\
\hline $8000-12,000$ & 152 & 26.9 & 254 & 34.8 \\
\hline $12,000-15,000$ & 118 & 20.9 & 249 & 34.1 \\
\hline$\geq 15,000$ & 102 & 18.1 & 104 & 14.2 \\
\hline
\end{tabular}

The right part of Table 2 shows the dimension of behavior and environment determined by Multiple Corresponding Analysis using the combined data. The scores in each of the three columns denote the level of contribution of each variable to the dimension. A positive score denotes the same direction of the variable and the dimension. A negative score denotes the opposite direction. Omitted cells with "_" denote very low $(<0.025)$ contribution of the dimension for that variable.

From the table, variables related to pig farms make a strong positive contribution to Dimension 1. We thereafter considered Dimension 1 as the "Pig rearing" dimension.

Variables related to bed nets, such as possessing bed nets, using bed nets in general, and using bed nets in the day contribute to Dimension 2. We named this dimension "Bed net use". It should, however, be noted that sleeping under a bed net during the daytime had an opposite direction compared to possessing bed nets and using bed nets in general.

Using repellents outside the house, using mosquito coils, and using floral water contribute to Dimension 3. We named this dimension "Repellent use".

It can be noticed that Dimension 3 is also affected to a small extent by the pig rearing variables in a negative direction. 
Table 2. Comparison of environmental factors and personal behaviors between the child group and adult group.

\begin{tabular}{|c|c|c|c|c|c|}
\hline \multirow[t]{2}{*}{ Variables } & $\begin{array}{c}\text { Child Group } \\
\text { (Age } \leq 18 \text { Years) }\end{array}$ & $\begin{array}{c}\text { Adult Group } \\
\text { (Age }>18 \text { Years) }\end{array}$ & Dimension 1 & Dimension 2 & Dimension 3 \\
\hline & $\%$ & $\%$ & \multicolumn{3}{|c|}{ Contribution Score } \\
\hline \multicolumn{6}{|l|}{ Pig rearing by family } \\
\hline Yes & 60 & 61.2 & 0.574 & _ & -0.379 \\
\hline No & 40 & 39.8 & -0.88 & - & 0.582 \\
\hline \multicolumn{6}{|l|}{ Distance from house to pig farm } \\
\hline Side of the house & 54.2 & 57.7 & 0.561 & 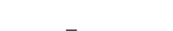 & -0.413 \\
\hline Less than $3 \mathrm{~km}$ & 5.8 & 3.4 & 0.97 & _- & \\
\hline Without pig rearing & 40.0 & 38.9 & -0.876 & - & $0 . \overline{584}$ \\
\hline \multicolumn{6}{|l|}{ With pig farm near the house } \\
\hline Yes & 34.9 & 42.5 & 0.921 & _ & -0.349 \\
\hline No & 65.1 & 57.5 & -0.57 & - & - \\
\hline \multicolumn{6}{|l|}{ Distance of the nearest pig farm } \\
\hline Side of the house & 28.1 & 34.2 & 1.022 & & -0.425 \\
\hline Less than $3 \mathrm{~km}$ & 6.8 & 8.3 & 0.722 & -0.939 & - \\
\hline Without pig rearing & 65.1 & 57.5 & -0.57 & - & - \\
\hline \multicolumn{6}{|l|}{ Housing structure } \\
\hline Wooden/bamboo structure & 24.2 & 19.6 & - & - & - \\
\hline Brick and cement structure & 71.4 & 77.5 & - & - & - \\
\hline Other & 4.4 & 2.8 & - & - & - \\
\hline \multicolumn{6}{|l|}{ With paddy field } \\
\hline Yes & 69.9 & 81.8 & _- & _ & _ \\
\hline No & 30.1 & 18.2 & - & _- & - \\
\hline \multicolumn{6}{|l|}{ Near to the forest } \\
\hline Yes & 23.2 & 25.7 & _- & _- & _- \\
\hline \multirow{2}{*}{\multicolumn{6}{|c|}{ With rubber planting }} \\
\hline & & & & & \\
\hline Yes & 60.4 & 68.1 & _ & & _ \\
\hline \multirow{2}{*}{\multicolumn{6}{|c|}{ With discarded tires }} \\
\hline & & & & & \\
\hline Yes & 17.1 & 20.0 & _ & _ & _ \\
\hline \multirow{2}{*}{\multicolumn{6}{|c|}{ With aquatic plants }} \\
\hline & & & & & \\
\hline Yes & 17.5 & 14.0 & _- & _ & _ \\
\hline No & 82.5 & 86.0 & - & - & - \\
\hline \multicolumn{6}{|l|}{ With pickle jars } \\
\hline Yes & 75.8 & 82.3 & _ & _ & _ \\
\hline \multirow{2}{*}{\multicolumn{6}{|c|}{$\begin{array}{l}\text { No } \\
\text { Running water }\end{array}$}} \\
\hline & & & & & \\
\hline Yes & 92.3 & 98.4 & _ & _ & _ \\
\hline No & 7.7 & 1.6 & - & - & - \\
\hline Tanks for water storage & & & & & \\
\hline Yes & 36.4 & 49.4 & _ & _ & _ \\
\hline No & 63.6 & 50.6 & - & - & - \\
\hline Family possesses bed nets & & & - & - & - \\
\hline Yes & 70.4 & 58.9 & _- & 0.558 & _- \\
\hline No & 29.6 & 41.1 & - & -1.504 & - \\
\hline Often using bed nets & & & & & \\
\hline Yes & 55.3 & 29.7 & _ & 0.921 & _ \\
\hline No & 44.7 & 70.3 & - & -0.729 & - \\
\hline Sleeping in bed net during dayt & & & & & \\
\hline Yes & 64.8 & 81.4 & _- & -0.548 & _- \\
\hline No & 35.2 & 18.6 & - & 1.18 & - \\
\hline Using insect repellent when working & & & & & \\
\hline Yes & 48.2 & 50.1 & 0.603 & _ & 0.739 \\
\hline No & 51.8 & 49.9 & -0.58 & - & -0.711 \\
\hline Using mosquito coils & & & & & \\
\hline Yes & 54.8 & 54.2 & 0.63 & _ & 0.753 \\
\hline No & 45.2 & 45.8 & -0.526 & - & -0.628 \\
\hline Using florial water when working/play & & & & & \\
\hline Yes & 72.9 & 80.0 & 0.711 & _- & 1.071 \\
\hline No & 27.1 & 20.0 & - & - & -0.339 \\
\hline Using DEET when working/playing & & & - & & \\
\hline Yes & 1.5 & 4.6 & _- & _- & _- \\
\hline No & 98.5 & 95.4 & - & - & - \\
\hline
\end{tabular}

Note: "_ variables are those which contributed less than $2.5 \%$ to three dimensions. The negative contribution scores denote the opposite direction.

\subsection{Univariate Analysis among the Sociodemographic Factors and Three Dimensions}

To simplify the analysis and for the purpose of effective communication, all three dimensions of behaviors were dichotomized. Pig rearing dimension scores of less than 0 were labeled as "good", or "bad" if otherwise. The opposite was true for the bed net and repellent use dimensions.

Table 3 summarizes the association between sociodemographic characteristics and each of three dimensions for all subjects. The $p$ value for each variable was based on Pearson's chi squared test for 
non-ordinal variables such as gender and ethnic group, and on chi-squared test for ordinal variables such as income, family size, and education level.

Gender was not associated with MBD behaviors in any dimension. In contrast, age group was associated with MBD behaviors in all dimensions. Compared with the adult group, the child group was more likely to have pig rearing environment, and not use repellent, but also more likely to use a bed net.

Table 3. Univariate analysis of association between the sociodemographic factors and pig rearing, bed net use, and repellent use.

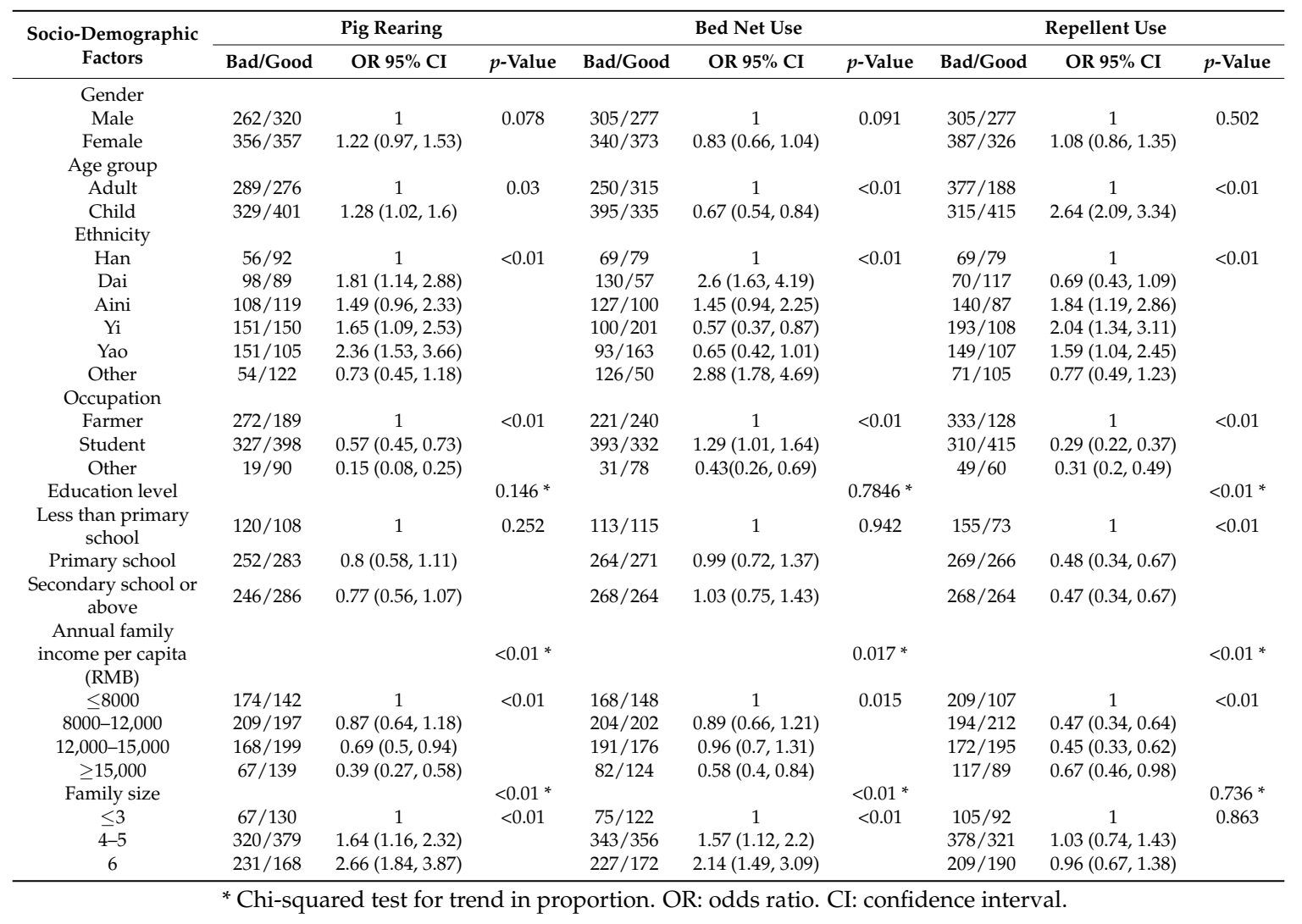

Compared to Han, the minority groups of Dai, Yi, and Yao were more likely have exposure to a pig rearing environment; Dai and "Others" were more likely to use a bed net, but the Yi ethnic group was less likely to use a bed net, and Aini, Yi, and Yao groups were more likely to use repellent.

Compared to farmer, students and those with other occupations were less likely to be exposed to a pig rearing environment and less likely to use repellent. Students were less likely to use bed nets and "others" more likely to use bed nets.

High education level was associated with low exposure to pig rearing, and higher exposure to bed net use.

Higher annual family income per capita was negatively associated with pig rearing and positively associated with bed net and repellent use. A person from a large family was more likely to rear pigs and less likely to use bed nets. There was no significant relationship between family size and repellent use.

\subsection{Results from Logistic Regression}

Table 4 summarizes the results of logistic regressions predicting "bad" behaviors of each of the three models related to mosquito-borne diseases.

Neither gender nor age group was significantly related to rearing pigs, bed net or repellent use. 
Han and "Other" ethnicities had the lowest odds of exposure to rearing pigs. Their odds were significantly lower than Yi and Yao. For bed net use, Dai and "Other" ethnicities were less likely to use bed nets, in contrast with Yi and Yao. The odds of repellent use behaviors in the Han ethnicity was lower than Yi, but higher than Dai.

Farmers (the reference group) were at higher risk for pig rearing and repellent non-use.

Education of less than primary school held the lowest odds of pig rearing.

Subjects with low income ( $\leq$ RMB 8000$)$ were at higher risk for not using bed nets or repellent.

Subjects with small family size were less likely to rear pigs.

Table 4. Associations between sociodemographic factors and bad MBD behaviors.

\begin{tabular}{|c|c|c|c|}
\hline \multirow{2}{*}{ Predictive Factors } & Model 1 Pig Rearing & $\begin{array}{c}\text { Model } 2 \text { Not Using } \\
\text { Bed Net }\end{array}$ & $\begin{array}{c}\text { Model } 3 \text { Not } \\
\text { Using Repellent }\end{array}$ \\
\hline & AOR 95\% CI & AOR 95\% CI & AOR 95\% CI \\
\hline Age group: Adult vs Child & $1.23(0.4,3.76)$ & $1.04(0.35,3.07)$ & $0.78(0.25,2.44)$ \\
\hline Gender: Female vs Male & $1.16(0.91,1.48)$ & $0.87(0.68,1.11)$ & $0.84(0.66,1.07)$ \\
\hline Ethnicity ref.: Han & $* * *$ & $* * *$ & $* * *$ \\
\hline Dai & $1.41(0.88,2.27)$ & $2.47(1.53,3.97)^{* *}$ & $0.45(0.28,0.74)^{* *}$ \\
\hline Aini & $1.14(0.73,1.78)$ & $1.32(0.85,2.03)$ & $1.32(0.84,2.06)$ \\
\hline Yi & $1.58(1.02,2.42)^{*}$ & $0.55(0.36,0.84)^{* *}$ & $1.59(1.04,2.43)$ * \\
\hline Yao & $1.86(1.19,2.9)^{* *}$ & $0.52(0.34,0.8)^{* *}$ & $1.25(0.8,1.94)$ \\
\hline Other & $0.64(0.4,1.04)$ & $2.44(1.52,3.92) * *$ & $0.9(0.57,1.43)$ \\
\hline Occupation Reference: Farmer & $* * *$ & $* * *$ & $* * *$ \\
\hline Student & $0.67(0.22,2.07)$ & $1.32(0.44,3.93)$ & $0.21(0.07,0.68) * *$ \\
\hline Other & $0.15(0.08,0.27)^{* *}$ & $0.39(0.22,0.67)^{* *}$ & $0.28(0.17,0.48)^{* *}$ \\
\hline $\begin{array}{l}\text { Education level Reference: Less } \\
\text { than primary school }\end{array}$ & $* * *$ & & \\
\hline Primary school & $1.5(1.01,2.22) *$ & $0.85(0.57,1.26)$ & $1.02(0.66,1.55)$ \\
\hline Secondary school or above & $1.99(1.33,2.96)^{* *}$ & $1.06(0.71,1.59)$ & $1.04(0.68,1.6)$ \\
\hline Annual family income (per capita & & & $* * *$ \\
\hline RMB) ref.: $\leq 8000$ (RMB) & & & \\
\hline $8000-12,000$ & $0.98(0.71,1.35)$ & $0.67(0.48,0.93) *$ & $0.61(0.44,0.85)^{* *}$ \\
\hline $12,000-15,000$ & $0.9(0.64,1.26)$ & $0.77(0.55,1.08)$ & $0.66(0.46,0.93)$ * \\
\hline$>15,000$ & $0.67(0.43,1.04)$ & $0.68(0.44,1.05)$ & $1.04(0.67,1.62)$ \\
\hline Family size ref. $\leq 3$ & $* * *$ & & \\
\hline $4-5$ & $1.41(0.98,2.04)$ & $1.17(0.81,1.68)$ & $1.33(0.92,1.92)$ \\
\hline$\geq 6$ & $2.11(1.4,3.18)^{* *}$ & $1.4(0.93,2.11)$ & $1.34(0.88,2.02)$ \\
\hline
\end{tabular}

\section{Discussion}

In this study, over half of the subjects were children. Although their ethnic backgrounds were different from those of the adult sample, their MBD-related behaviors were similar. Yi and Aini groups dominated in the adult sample, whereas "Other", Yao, and Yi contributed significantly to the child group. MCA helped to reduce the number of behavior variables to only three domains, namely, pig rearing environment, bed net use behaviors, and repellent use behaviors. Han and "Other" ethnic groups had the lowest odds of rearing pigs; Yi and Yao were mostly likely to use bed nets and Dai was most likely to use repellent. Farmer was the most likely occupation to rear pigs and not use repellent. Income had no significant relation to pig rearing and bed net use. In general, the middle-income group (CNY¥ 8000-12,000) was more likely to use repellent.

Pig rearing is a known risk factor for Japanese Encephalitis virus, because pigs are an important amplifying host. Studies conducted in India [10-12], Republic of Korea [13,14], Nepal [15], and China [16] showed the same results. The need for the vaccination of local residents and pigs against JEV is often considered $[17,18]$. However, this is not practical in the study areas. Farmers were more likely to rear pigs because of economic and food needs. Han and "Other" ethnic groups were 
less likely to rear pigs. The reasons for this ethnic influence and whether these two ethnic groups have lower incidence of JEV is not known.

Bed net use can prevent various mosquito-borne diseases. The most successful field is malaria prevention and control $[19,20]$. Local health systems have been trying to promote bed net use, especially long-lasting insect treated bed nets for malaria prevention. This was not very successful as the percentage of bed net use was only slightly higher than $50 \%$. Research performed on the use of bed nets among minority groups indicated that human, socioeconomic, and environmental factors can all affect the use of bed nets in China [5,7] and Solomon Islands [6]. Bed net use became compulsory for US soldiers in the Pacific during World War II following severe outbreaks of malaria and dengue fever [21,22]. International health groups are providing long-lasting, insecticide-treated nets to residents in malaria endemic areas of underdeveloped countries, particularly in Africa. In such areas, the regular use of insecticide-treated bed nets can reduce childhood mortality up to $20 \%$ and severe disease up to $50 \%[23,24]$. In sub-Saharan Africa, insecticide-treated nets are popular method of malaria control [25]. Our study showed that the relatively high percentage of bed net use among Yi and Yao should be a good example for other ethnic groups to follow.

Repellent use in the study varied considerably. Repellents are used by individuals to reduce the number of bites from hematophagous arthropods [26]. Such products include topical repellents applied directly to the skin, but they also include compounds on clothing, insecticide-treated bed nets, and various devices that emit vapor or droplets into a small space (e.g., mosquito coils) [27]. A study conducted in Yunnan, China, revealed that personal protection is widely used and accepted, with the major barrier to its use being affordability [28]. Research conducted in India showed that repellents are widely used in India. Their using is influenced by the level of education and socioeconomic status [29]. The current study indicated that the Dai ethnicity was more likely to use repellent, probably because they spend a lot of time in rubber plantations.

\section{Limitation}

This study was based on a questionnaire, not direct observation. More than half of the respondents were children, who might give inaccurate information. The extent of information bias is unknown. Thus, this cross-sectional survey may capture only a snapshot of information about the participants; the findings may change with time.

\section{Conclusions}

Along China-Laos border areas, ethnic minority groups vary their exposure to pig rearing, their bed net use behaviors, and repellent use behaviors. The behaviors are also influenced by other sociodemographic factors. These influences should be taken into account in the control of mosquito-borne diseases.

Acknowledgments: The authors are grateful to staff of the Xishuangbanna Prefecture CDC: Jianhua Fan for supporting the fieldwork, the Mengla County CDC: Junming Li, Huaxing Liu, Yujiang Xiao and all the staffs of five study sites Health center for supporting the fieldwork. This research was supported by the National Natural Science Fund of China (Nos. 81560548, U1602223, 81160357, 30960327, 30660160); Yunnan Science and Technology Major Project (2017ZF007), and the Joint Control Project of Malaria and Dengue in China's frontier areas adjacent to Laos, China.

Author Contributions: Conceived and designed the experiments: Virasakdi Chongsuvivatwong, Chao Wu, Xiaofang Guo, Hongning Zhou. Analyzed the data: Chao Wu, Jun Zhao, Virasakdi Chongsuvivatwong, Edward B. McNeil. Wrote the paper: Chao Wu, Virasakdi Chongsuvivatwong, Jun Zhao, Hongning Zhou, Xiaofang Guo. Collected data: Chao Wu, Quan Lv, Hongbin Li. Defined the scope of the research: Virasakdi Chongsuvivatwong, Chao Wu, Hongning Zhou. Performed statistical analyses: Jun Zhao, Chao Wu, Virasakdi Chongsuvivatwong, Edward B. McNeil. Jointly discussed manuscript: Chao Wu, Virasakdi Chongsuvivatwong, Jun Zhao, Hongning Zhou, Xiaofang Guo, Hongbin Li, Quan Lv.

Conflicts of Interest: All authors declare that they have no conflicts of interest. 


\section{Abbreviations}

MBD mosquito-borne diseases

MCA multiple correspondence analysis

\section{References}

1. Phommanivong, V.; Kanda, S.; Shimono, T.; Lamaningao, P.; Darcy, A.W.; Mishima, N.; Phaytanavanh, B.; Nishiyama, T. Co-circulation of the dengue with chikungunya virus during the 2013 outbreak in the southern part of Lao PDR. Trop. Med. Health 2016, 44, 24. [CrossRef] [PubMed]

2. Guo, X.; Yang, H.; Wu, C.; Jiang, J.; Fan, J.; Li, H.; Zhu, J.; Yang, Z.; Li, Y.; Zhou, H. Molecular characterization and viral origin of the first dengue outbreak in Xishuangbanna, Yunnan Province, China, 2013. Am. J. Trop. Med. Hyg. 2015, 93, 390-393. [CrossRef] [PubMed]

3. Zhou, S.; Yang, R.; Lv, Q.; Yang, Z.; Du, L. Situation analysis of insecticide treatment bed net in Yunnan malaria endemic areas and its generalization strategy. Chin. J. Vector Bio. Control 2009, 20, 326-328.

4. Li, B.; Yang, Y.; Xu, J.; Chen, G.; Zhou, S.; Zhao, X.; Yang, R.; Shen, J.-Y.; Lv, Q.; Huan, G.-Z. Baseline investigation of the National Malaria Elimination program and projects funded by the Global Malaria Fund in Yunnan Province. J. Pathog. Biol. 2013, 8, 448-450.

5. Xu, J.; Xia, M.; Petlueng, P.; Tao, H.; Zhong, Y.; Wu, X.; Liu, S.; Wen, Z.; Liu, H. Current situation, attitudes and scaling up obstacles toward usage of bednets in Wa ethnic. China Trop. Med. 2004, 4, 319-321.

6. Atkinson, J.-A.; Bobogare, A.; Fitzgerald, L.; Boaz, L.; Appleyard, B.; Toaliu, H.; Vallely, A. A qualitative study on the acceptability and preference of three types of long-lasting insecticide-treated bed nets in Solomon Islands: implications for malaria elimination. Malar. J. 2009, 8, 119. [CrossRef] [PubMed]

7. Xu, J.-W.; Liao, Y.-M.; Liu, H.; Nie, R.-H.; Havumaki, J. Use of bed nets and factors that influence bed net use among Jinuo ethnic minority in Southern China. PLoS ONE 2014, 9, e103780. [CrossRef] [PubMed]

8. Lê, S.; Josse, J.; Husson, F. FactoMineR: An R package for multivariate analysis. J. Stat. Softw. 2008, 25, 1-18. [CrossRef]

9. Nenadic, O.; Greenacre, M. Correspondence analysis in R, with two-and three-dimensional graphics: The Ca Package. J. Stat. Softw. 2007, 20, 1-13.

10. Phukan, A.; Borah, P.; Mahanta, J. Japanese encephalitis in Assam, northeast India. Southeast Asian J. Trop. Med. Public Health 2004, 35, 618-622. [PubMed]

11. Dwibedi, B.; Mohapatra, N.; Rathore, S.K.; Panda, M.; Pati, S.S.; Sabat, J.; Thakur, B.; Panda, S.; Kar, S.K. An outbreak of Japanese encephalitis after two decades in Odisha, India. Indian J. Med. Res. 2015, 142, S30-S32. [CrossRef] [PubMed]

12. Khan, S.; Narain, K.; Handique, R.; Dutta, P.; Mahanta, J.; Satyanarayana, K.; Srivastava, V. Role of some environmental factors in modulating seasonal abundance of potential Japanese encephalitis vectors in Assam, India. Southeast Asian J. Trop. Med. Public Health 1996, 27, 382-391. [PubMed]

13. Richards, E.E.; Masuoka, P.; Brett-Major, D.; Smith, M.; Klein, T.A.; Kim, H.C.; Anyamba, A.; Grieco, J. The relationship between mosquito abundance and rice field density in the Republic of Korea. Int. J. Health Geogr. 2010, 9, 32. [CrossRef] [PubMed]

14. Masuoka, P.; Klein, T.A.; Kim, H.-C.; Claborn, D.M.; Achee, N.; Andre, R.; Chamberlin, J.; Small, J.; Anyamba, A.; Lee, D.-K. Modeling the distribution of Culex tritaeniorhynchus to predict Japanese encephalitis distribution in the Republic of Korea. Geosp. Health 2010, 5, 45-57. [CrossRef] [PubMed]

15. Impoinvil, D.E.; Solomon, T.; Schluter, W.W.; Rayamajhi, A.; Bichha, R.P.; Shakya, G.; Caminade, C.; Baylis, M. The spatial heterogeneity between Japanese encephalitis incidence distribution and environmental variables in Nepal. PloS ONE 2011, 6, e22192. [CrossRef] [PubMed]

16. Yang, Y.; Liang, N.; Tan, Y.; Xie, Z. Epidemiological trends and characteristics of Japanese encephalitis changed based on the vaccination program between 1960 and 2013 in Guangxi Zhuang Autonomous Region, southern China. Int. J. Infect. Dis. 2016, 45, 135-138. [CrossRef] [PubMed]

17. Zheng, Y.; Li, M.; Wang, H.; Liang, G. Japanese encephalitis and Japanese encephalitis virus in mainland China. Rev. Med. Virol. 2012, 22, 301-322. [CrossRef] [PubMed]

18. Heffelfinger, J.D. Japanese Encephalitis Surveillance and Immunization-Asia and Western Pacific Regions, 2016. MMWR Morb. Mortal. Wkly. Rep. 2017, 66, 579-583. [CrossRef] [PubMed]

19. World Health Organization. World Malaria Report 2016: Summary; WHO: Geneva, Switzerland, 2017. 
20. Tolle, M.A. Mosquito-borne diseases. Curr. Probl. Pediatr. Adolesc. Health Care 2009, 39, 97-140. [CrossRef] [PubMed]

21. Sapero, J.J. The malaria problem today: Influence of wartime experience and research. J. Am. Med. Assoc. 1946, 132, 623-627. [CrossRef] [PubMed]

22. Kitchen, L.W.; Lawrence, K.L.; Coleman, R.E. The role of the United States military in the development of vector control products, including insect repellents, insecticides, and bed nets. J. Vector Ecol. 2009, 34, 50-61. [CrossRef] [PubMed]

23. Lindsay, S.; Adiamah, J.; Miller, J.; Armstrong, J.R.M. Parathyroid-treated bed net effects on mosquitoes of the Anopheles gambiae complex in The Gambia. Med. Vet. Entomol. 1991, 5, 477-483. [CrossRef] [PubMed]

24. Gimnig, J.E.; Kolczak, M.S.; Hightower, A.W.; Vulule, J.M.; Schoute, E.; Kamau, L.; Phillips-Howard, P.A.; ter Kuile, F.O.; Nahlen, B.L.; Hawley, W.A. Effect of permethrin-treated bed nets on the spatial distribution of malaria vectors in western Kenya. Am. J. Trop. Med. Hyg. 2003, 68, 115-120. [PubMed]

25. Lengeler, C. Insecticide-Treated Bed Nets and Curtains for Preventing Malaria (Review); John Wiley \& Sons, Ltd.: New York City, NY, USA, 2004.

26. White, G. Terminology of insect repellents. In Insect Repellents. Principles, Methods and Uses; Debboun, M., Frances, S.P., Strickman, D., Eds.; CRC Press: Boca Raton, FL, USA, 2007.

27. Strickman, D.; Frances, S.P.; Debboun, M. Prevention of Bug Bites, Stings, and Disease; Oxford University Press: Oxford, UK, 2009.

28. Moore, S.J.; Min, X.; Hill, N.; Jones, C.; Zaixing, Z.; Cameron, M.M. Border malaria in China: Knowledge and use of personal protection by minority populations and implications for malaria control: A questionnaire-based survey. BMC Public Health 2008, 8, 344. [CrossRef] [PubMed]

29. Van Eijk, A.M.; Ramanathapuram, L.; Sutton, P.L.; Peddy, N.; Choubey, S.; Mohanty, S.; Asokan, A.; Ravishankaran, S.; Priya, G.S.L.; Johnson, J.A. The use of mosquito repellents at three sites in India with declining malaria transmission: surveys in the community and clinic. Parasites Vectors 2016, 9, 418. [CrossRef] [PubMed]

(C) 2017 by the authors. Licensee MDPI, Basel, Switzerland. This article is an open access article distributed under the terms and conditions of the Creative Commons Attribution (CC BY) license (http:/ / creativecommons.org/licenses/by/4.0/). 